\title{
Politicas Públicas e Extrafiscalidade: Direitos FundAMENTAIS DA JUVENTUDE BRASILEIRA
}

\author{
Hugo Thamir Rodrigues \\ Fabiano Rodrigo Dupont*
}

\begin{abstract}
Considerações Iniciais. 1 papel do poder público na construção de políticas públicas efetivadoras dos direitos da juventude brasileira. 2 A finalidade extrafiscal da norma tributária como mecanismo de implementação de políticas públicas. $3 \mathrm{~A}$ extrafiscalidade tributária enquanto política pública de desenvolvimento e de inclusão social de jovens. Considerações Finais. Referências.
\end{abstract}

\section{RESUMO}

O objetivo com o presente estudo é analisar a relação existente entre políticas públicas e extrafiscalidade de tributos com base no agir público na consolidação de direitos fundamentais da juventude brasileira. Diante desse cenário, são pontuados e discutidos o atual papel do poder público na construção de políticas públicas efetivadoras dos direitos da juventude. Cotejados estes aspectos, apresenta-se a finalidade extrafiscal da norma tributária como mecanismo de implementação de políticas públicas. E a partir disso, analisa-se a possibilidade e o desenvolvimento de políticas públicas com o intuito da inclusão social de jovens no cenário brasileiro. Para tal feito, utiliza-se o método hipotético-dedutivo, através de levantamento bibliográfico.

Palavras-chave: Função extrafiscal. Direitos fundamentais. Políticas públicas. Juventude.

\section{CONSIDERAÇÕES INICIAIS}

A juventude brasileira, especialmente se considerado os últimos dez anos, tem ocupado cada vez mais espaço na agenda pública com a discussão e implementação de políticas públicas com a finalidade da proteção social, inserção profissional e o incentivo a sua participação política. Colaborando com essa inserção, em agosto de 2013 foi editado o Estatuto da Juventude, que findou com um processo de quase dez anos de lutas e discussões por garantias de direitos dessa porção da população.

* Graduado em Direito pela Universidade de Santa Cruz do Sul. Mestrado em Desenvolvimento Regional pela Universidade de Santa Cruz do Sul. Doutor em Direito pela Universidade Federal de Santa Catarina. Professor adjunto da Universidades de Santa Cruz do Sul e de Passo Fundo.

** Graduado e mestrando em Direito pela Universidade de Santa Cruz do Sul (UNISC). 
Neste contexto, o objetivo do presente estudo é a realização de uma análise sistemática da utilização da função extrafiscal da norma tributária como mecanismo de implementação de políticas públicas com base no agir público e na consolidação de direitos fundamentais da juventude brasileira. Para tanto, dividiu-se o trabalho em três momentos, no primeiro deles discorre-se sobre o papel do poder público na construção de políticas públicas efetivadoras dos direitos da juventude brasileira, partindo do pressuposto que o mundo encontra-se em constante transformação e os jovens da atualidade vivenciam problemas e incertezas de seu tempo.

Assentados estes aspectos, migra-se para o estudo da finalidade extrafiscal da norma tributária como mecanismo de implementação de políticas públicas, onde o objetivo principal é a sua utilização na redistribuição de rendas e de terras, a defesa da indústria nacional, a orientação de certos investimentos em setores estratégicos de produção, mas, principalmente no incentivo a jovens que carecem de ações efetivas de cidadania.

E dessa forma, conclui-se o trabalho analisando a utilização da extrafiscalidade tributária enquanto política pública de desenvolvimento e inclusão social de jovens no atual mundo globalizado, uma vez que diante do cenário de exclusão social, tem-se uma parcela da juventude brasileira que se vê às margens do sistema de proteção dos direitos e garantias fundamentais.

\section{O PAPEL DO PODER PÚBLICO NA CONSTRUÇÃO DE POLÍTICAS PÚBLICAS EFETIVADORAS DOS DIREITOS DA JUVENTUDE BRA- SILEIRA}

Em meio às inúmeras transformações na sociedade, tanto de caráter econômico, político e social, o ocaso do século XX e o início do século XXI se travestem de novos significados, onde conceitos como os de crianças, adolescentes e jovens adquirem uma determinada dimensão social até então não conhecida no mundo ocidental. A partir desse momento deixam de ser unicamente um objeto de interesse, preocupação e ação no âmbito privado da família e da igreja para tornar-se uma questão de cunho social, sendo assim, de competência não só do Estado, mas também da sociedade.

Deste modo, crianças, adolescentes e jovens deixam de ocupar uma posição secundária tanto na família quanto na sociedade e passam a ser compreendidos como um valioso patrimônio da nação ${ }^{1}$, a chave para o futuro. Sendo, assim, nas palavras de Rizzini, "um ser em formação - 'dúctil e moldável' - que tanto pode ser transformado em 'homem de bem' (elemento útil para o progresso da nação) ou num 'degenerado' (um vicioso inútil a pesar nos cofres públicos)”. ${ }^{2}$

Nesse sentido, ao se buscar na literatura histórica referências sobre o espaço que era destinado a esses indivíduos na sociedade brasileira, verifica-se incontestavelmente que a criança, o adolescente e o jovem que mais aparecia era aquele que, para os olhos da elite do século XX, era desprovido de proteção por 
parte do Estado e, portanto, necessitava ser corrigido ou reeducado. Na exata definição de Rizzini eram os “'expostos', os 'orphaosinhos', os 'pobres meninos abandonados', as 'crianças criminosas' os 'menores delinquentes' e assim por diante. Onde constava algo relativo à infância ou à juventude, lá estava implícita a ideia de periculosidade" ${ }^{3}$

Todavia, a partir da segunda metade da década de 1990, o tema da juventude inicia a sua trajetória de projeção e complexidade diante do espaço público brasileiro. E assim sendo, ao mesmo tempo em que ocorria o aumento do número de jovens de 15 a 24 anos na sociedade, eram os mesmos afetados de maneira especialmente intensa em razão das profundas desigualdades econômicas e sociais, enfrentando dificuldades das mais diversas. ${ }^{4}$

Desta maneira, a condição juvenil refere-se principalmente ao modo como a sociedade organizada atribui a definição a esse momento do ciclo da vida, especificando uma dimensão histórico-geracional, à medida que a situação desses jovens evidencia o modo como tal etapa é vivida com base nos mais diferentes recortes - social, classe, gênero, etnia, entre outros. ${ }^{5}$

E, portanto, é nesse período, da juventude, que se inicia o processo de inserção nas diversas dimensões da idade adulta. Como lembra Abramo ${ }^{6}$, é "na constituição de famílias, no mundo do trabalho e nos espaços de cidadania. Assim sendo, na etapa da juventude se definem possibilidades e impossibilidades de inserção na vida produtiva e social, de desenvolvimento de projetos pessoais e sociais".

Por conta desse processo, utilizando-se dos ensinamentos de $\mathrm{Abad}^{7}$, a infância quase desapareceu, rodeada por uma adolescência que desabrocha muito cedo e uma juventude que se prolonga até depois dos 30 anos, o que acaba significando que quase um terço da vida e um terço da população tem esse rótulo, indeterminado e convencional como todos, porém simbolicamente intenso.

Ou seja, no atual momento histórico, a juventude, com sua diversidade, não pode ser vista apenas como momento de passagem. Em diferentes ritmos e intensidades, tais fenômenos aproximam jovens das economias centrais e periféricas. Pode-se dizer que nunca houve tanta conexão globalizada e, ao mesmo tempo, nunca foram tão agudos e profundos os sentimentos de desconexão. ${ }^{8}$

Então, a juventude poderia ser enquadrada como um período de privações, com escassa autonomia e constantes constrangimentos pelas convenções sociais, sendo caracterizada como uma etapa dura de aprendizagem das coisas para a vida, que todos deveriam passar com o intuito de adquirir suficiente experiência, normalmente de maneira penosa e árdua, antes de chegar à vida adulta. ${ }^{9}$

Contudo, como habitante de um mundo que se encontra em constante transformação, a juventude atual vive problemas e incertezas de seu tempo. Para Abramo essa juventude revela as "desigualdades econômicas, disparidades regionais, dicotomias entre campo e cidade, assim como preconceitos e discriminações 
(de gênero, raça-etnia, orientação sexual, religião, etc.)" ${ }^{10}$, que acabam afastando os jovens de classes e grupos sociais distintos.

E atrelado aos dias atuais, enquanto uma determinada parcela de crianças, adolescentes e principalmente jovens se prepara para ingressar na vida adulta por intermédio da educação, outros buscam condições para que possam conciliar educação e trabalho. Porém, para todos está posta a questão da entrada e da permanência no mercado de trabalho, sendo este, cada vez mais caracterizado pela irregularidade, pela descontinuidade, pela precariedade de salário e por sua informalidade. ${ }^{11}$

Entretanto, sabe-se que o Estado deve ser instrumental, tendo forte parcela de responsabilidade no desenvolvimento da sociedade, no bem-estar da população,

[...] e o governo por gerenciar o alcance desses objetivos por meio da elaboração de políticas públicas ou macroeconômicas. Para isso, ele planeja, pesquisa, identifica, formula e reformula políticas, programas e projetos. Entretanto, todos os agentes são responsáveis pela condição de desenvolvimento, e, partindo-se disso, justifica-se também a participação do setor privado na contribuição para a formulação de políticas que tenham finalidade igual. ${ }^{12}$

Nessa situação, as políticas públicas tornaram-se ferramentas adequadas para a efetivação das ações políticas e desse modo à concretização de direitos fundamentais e sociais. Para tanto, imperioso que se faça uma abordagem, ainda que superficial, vez que esse estudo não esgota o assunto, dos conceitos metodológicos das políticas públicas.

Inicialmente, importa elucidar que a análise das políticas públicas não pode ser feita de maneira fragmentada e isolada, ela deve estar relacionada, especialmente, com as questões que permeiam o Estado e a sociedade, pois "elas são o resultado da política, compreensíveis à luz das instituições e dos processos políticos, os quais estão intimamente ligados às questões mais gerais da sociedade" ${ }^{13}$ Assim, pode-se dizer que as políticas públicas são um conjunto de ações adotadas pelo governo, a fim de produzir efeitos específicos, ou de modo mais claro, a soma de atividades do governo que acabam influenciando a vida dos cidadãos.

E dessa maneira, seja pelo envolvimento de todos os membros da sociedade tanto na formulação quanto na avaliação das políticas públicas implementadas, ou ainda, seja pelo fato de centros de discussões e decisões para que se escolham ações específicas para estas, com o principal objetivo de alcançar o desenvolvimento sustentável, deve-se buscar e ponderar os indicadores que se adaptem a partir de todos os resultados e objetivos pretendidos e que detenham as políticas públicas em sua instância viabilizadora. ${ }^{14}$

Nesse contexto, um terreno ainda por ser efetivamente explorado é aquele no qual se encontra a análise das políticas públicas para a juventude, onde até 
o momento tem se situado no campo da ciência política, a qual prefere dar o enfoque a partir de seu aspecto técnico, isto é, o produto (policy) da atividade intermediário público, os denominados policy makers. E a partir do interesse constituído e do problema busca-se encontrar boas políticas ao mesmo tempo eficazes e eficientes com a finalidade de suavizar as arestas problemáticas da relação juventude versus sociedade adulta, para que juntas consigam diminuir as situações que podem acarretar a exclusão social. ${ }^{15}$

Por tal motivo, nas palavras de Silva e Souza-Lima, tanto o processo de elaboração quanto o de implementação de uma política pública devem estar alinhavados com os objetivos e as finalidades que se pretendem alcançar, "com a realidade das pessoas que participam do processo de amadurecimento e com a dimensão do desenvolvimento sustentável que se pretende atingir, possui caráter interdisciplinar" ${ }^{16}$. Assim, as políticas públicas são compreendidas como interdisciplinas no momento em que, de acordo com a sua diversidade e seus mais variados objetivos, podem alcançar dimensões distintas do desenvolvimento sustentável.

Diante disso,

[...] as políticas públicas são respostas que não ocorrerão a menos que haja uma provocação. Em linguagem mais especializada, as políticas públicas se destinam a solucionar problemas políticos, que são as demandas que lograram ser incluídas na agenda governamental. Enquanto essa inclusão não ocorre, o que se tem são 'estados de coisas': situações mais ou menos prolongadas de incômodo, injustiça, insatisfação ou perigo que atingem grupos mais ou menos amplos da sociedade sem, todavia, chegar a compor a agenda governamental ou mobilizar as autoridades políticas. ${ }^{17}$

Portanto, analisando as políticas públicas com base em sua acepção mais genérica tem-se que se caracterizam pelo conjunto de ações articuladas com recursos próprios, sejam eles financeiros ou humanos, e envolvem uma dimensão temporal e uma capacidade de impacto. Onde, para $\mathrm{Abad}^{18}$ o termo pode ser compreendido a partir de sua dimensão ético-política da finalidade da ação, e deve se aliar, fundamentalmente, a um projeto de desenvolvimento econômico-social e provocar maneiras de interação do Estado com a sociedade.

E a partir dessa concepção, busca-se a análise e elaboração de políticas públicas voltadas para a juventude, o que, tanto no Brasil quanto internacionalmente, é bastante recente. Contudo, como visto, o processo de transformação da tecnologia atrelado a intensificação dos mercados, em uma era globalizada, fez emergir, na concepção de Abramo $^{19}$, uma nova divisão internacional do trabalho evidenciando situações de pobreza e precarização das relações, onde tais mudanças sociais, incluindo aquelas que as acompanharam, atingem diretamente a juventude.

De acordo com uma pesquisa publicada pelo jornal Correio do Povo, no Brasil em 2011 existiam mais de 3,6 milhões de crianças e adolescentes em condição de trabalho infantil. Nesse cenário, de janeiro de 2014 a maio de 2015, 
521 crianças e jovens foram flagrados em condição de trabalho infantil das 975 inspeções realizadas pelas equipes da Superintendência Regional do Trabalho e Emprego do Rio Grande do Sul. O que, ainda segundo a pesquisa, motivou $25 \%$ dos casos de evasão escolar, colocando o Estado brasileiro na vice liderança na América Latina desse ranking lastimável. ${ }^{20}$

Ainda, segundo uma pesquisa divulgada pelo jornal Zero Hora a taxa de desemprego no país chegou a 8,3\% no período de abril a junho de 2015, maior nível da série que iniciou em 2012. Já no Estado do Rio Grande do Sul também houve avanço, contudo, um pouco inferior aos patamares nacional, cerca de $5,9 \%$. Assim, a partir da análise do gráfico abaixo pode se compreender que o desemprego entre a juventude brasileira tem o maior percentual no país. ${ }^{21}$

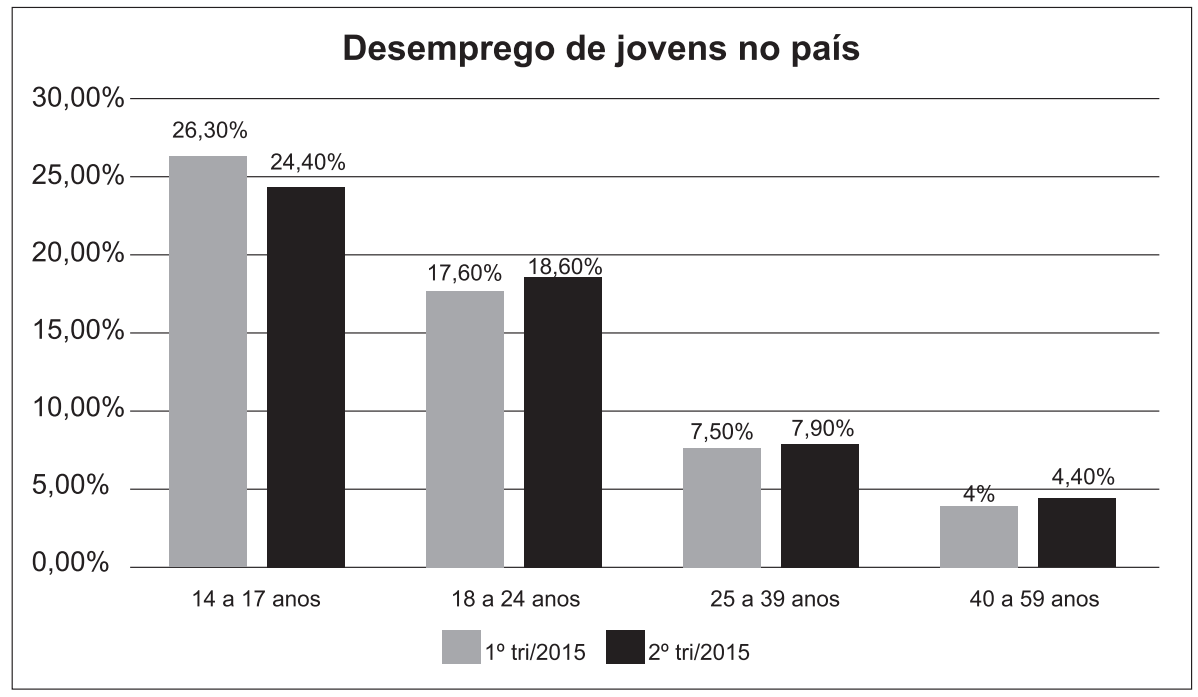

Fonte: Jornal Zero Hora (2015, p. 16).

Nesse mesmo sentido, importante ressaltar também a matéria publicada pelo Jornal Gazeta do Sul em que se assegura que o contingente que mais sofre com o aumento do desemprego é a juventude, especialmente naquela parcela que estava dedicada exclusivamente aos estudos e que agora, para complementação da renda familiar, necessitou ir ao mercado de trabalho. Desse modo, o coordenador de Trabalho e Rendimento do IBGE Cimar Azeredo afirma que "se a renda do chefe de família não é suficiente, o jovem tem de ir para a fila de emprego". ${ }^{22}$

Diante desse cenário e da atual crise mundial, bancos, governos e organismos internacionais buscam ao mesmo tempo sair do colapso e superar a pobreza instalada discutindo os problemas da juventude. Uma vez que, a fragilidade do atual modelo econômico foi revelada, colocando-se a necessidade de se pensar políticas públicas de e para a juventude. 
Assim neste contexto de políticas públicas está a finalidade extrafiscal da norma tributária, enquanto propagador do desenvolvimento social atrelado a atenção à juventude. Assunto este, tratado na sequência.

\section{A FINALIDADE EXTRAFISCAL DA NORMA TRIBUTÁRIA COMO MECANISMO DE IMPLEMENTAÇÃO DE POLÍTICAS PÚBLICAS}

O conceito jurídico para o ordenamento brasileiro de tributos está elencado no artigo terceiro do Código Tributário Nacional, cujos termos estabelecem como sendo "toda prestação pecuniária compulsória, em moeda ou cujo valor nela se possa exprimir, que não constitua sanção de ato ilícito, instituída em lei e cobrada mediante atividade administrativa plenamente vinculada”. Sendo assim, na definição de Ataliba ${ }^{23}$, apresenta-se como uma obrigação jurídica pecuniária, onde o sujeito ativo é uma pessoa pública, podendo ocorrer à delegação, e o sujeito passivo qualquer indivíduo que a legislação assim o caracterizou.

Nesse sentido, compreender o tributo como o meio de obtenção de receita para o Estado importa referir à finalidade mais basilar do direito tributário que neste caso é a finalidade fiscal. Deste modo, a fiscalidade consiste na utilização de mecanismos para "prover o caixa do Estado (entes federados) de recursos, destinados a fazer frente às despesas estatais. $O$ conceito é simples e geral e vale tanto para o direito tributário quanto para o direito financeiro". ${ }^{24}$

Portanto, o tributo tem como principal objetivo arrecadar recursos para que consiga suprir as necessidades dos cofres públicos decorrendo da supremacia do interesse público em detrimento do interesse particular, isto é, no entendimento de Balthazar ${ }^{25}$ a finalidade fiscal do tributo enquadra-se na arrecadação de receita visando à satisfação das necessidades públicas.

Contudo, o tributo pode ser compreendido a partir de suas outras finalidades, como é o caso da extrafiscalidade ${ }^{26}$, onde o Estado não almeja prioritariamente a arrecadação de valores para os cofres públicos, pelo contrário, visa otimizar ações que estimulem ou desestimulem certas formas de agir, seja aumentando (IPI sobre o cigarro, por exemplo) ou reduzindo (descontos sobre o IPVA para bons motoristas, por exemplo) a carga tributária. Deste modo, a função extrafiscal busca estimular ou desestimular determinados comportamentos por intermédio da tributação progressiva ou regressiva, ou ainda, da concessão de benefícios e incentivos fiscais.

Tipke, ao falar de grupos de normas tributárias, utiliza, para designar extrafiscalidade, a expressão "normas de redistribuição, dizendo que:

[...] estas objetivam correção do Bem Estar (Wohlstandskorrektur) no interesse de um equilíbrio social. Favorecimentos fiscais multiplicadores do Bem Estar são justificáveis segundo o princípio da necessidade [...]. Com tudo isso, o princípio do Estado social é útil à justificação de normas de redistribuição [...]. ${ }^{27}$ 
Assim sendo, essa finalidade do tributo força o cidadão a obtenção de comportamentos com o objetivo de se alcançar um determinado fim onde o interesse público deve sempre sobrepor sobre o interesse particular.

Sempre que os interesses da comunidade [...] estejam em discussão, os interesses particulares deverão ceder espaço a fim de que os primeiros sejam preservados, e, com isto, a segurança [...] seja resguardada. Assim, por exemplo, o combate ao desemprego, ou a preservação do nível do emprego a utilização racional da propriedade a fim de que a mesma cumpra com sua função social, a preservação do meio ambiente e de condições fitossanitárias mínimas para a sobrevivência do homem $\left[. . .{ }^{28}\right.$

Neste contexto, a indução por parte do Estado de determinados comportamentos mediante vantagem fiscal será exercido sobre aqueles que se enquadrarem nos requisitos legais, se a isenção for individual, podendo ser geral em isenções de caráter universal. Silva ${ }^{29}$, por seu turno, afirma que uma isenção geral pode vir acompanhada de carga extrafiscal, onde, por exemplo, se direciona "objetivamente, à produção do álcool combustível, estimula seu consumo em prejuízo do consumo de gasolina". Ou também quando se direciona, "subjetivamente, aos fabricantes de malhas têxteis, favorece o aparecimento de indústrias desse tipo de vestuário em detrimento dos curtumes".

Destarte, importante lembrar que isenções fiscais, a partir de seu efeito extrafiscal, tanto podem ter efeitos no âmbito de uma determinada região do país ou do estado, onde se busca um objetivo específico como pode ser irrestrito territorialmente, quanto os efeitos dessa extrafiscalidade poderão ser observados em toda a extensão do território.

E diante desse cenário, tem-se como objeto desse estudo a finalidade extrafiscal da norma tributária como mecanismo de implementação de políticas públicas, onde, de acordo com Schoueri ${ }^{30}$ essa utilização do tributo é fruto de uma evolução que já se verifica em outros ordenamentos jurídicos, quando se propõem a intervir de forma ativa no campo socioeconômico com a finalidade de tutela, de redistribuição e de equilíbrio das relações sociais. À vista disso, diante das realidades do Estado, além de as normas de direito financeiro/tributário serem um meio de assegurar a cobertura de despesas públicas, podem, com o mesmo ímpeto, intervir e auxiliar a regular a vida social, possibilitando realizações de natureza estrutural que influenciem de forma direta e indireta na qualidade de vida de cada um dos que compõem o conjunto de pessoas que habita o país.

Todavia, a aplicação da extrafiscalidade em nome do interesse coletivo não necessita estar atrelada a perda de numerário, quando do aumento ou diminuição de alíquotas ou bases de cálculos, como ensina Martins ${ }^{31}$, ao exemplificar esse processo quando ocorre a exacerbação da tributação sobre o consumo de cigarros, podendo, além de desestimular o consumo, aumentar a arrecadação. 
Neste sentido, toda e qualquer finalidade tributária não arrecadatória enquadrar-se-á como conotação extrafiscal. $\mathrm{O}$ que não excluirá a sua função fiscal, podendo ambos conviver de forma harmônica no ordenamento tributário, ocorrendo somente, segundo Martuscelli ${ }^{32}$, a não exclusividade de um fim, mas sim a preponderância de um determinado fim sobre o outro, neste caso, a extrafiscalidade sobre a fiscalidade.

Com isso se quer dizer, pragmaticamente, que dentre as ferramentas que o Estado se vale para intervir no campo socioeconômico almejando promover a justiça social, com regulação do mercado, redistribuição de riqueza, equilíbrio da balança, inclusão social etc. - está o direito tributário, que disponibiliza através da função extrafiscal do tributo que se façam políticas públicas com a utilização das normas tributárias. ${ }^{33}$

Portanto, a promoção de políticas públicas a partir da utilização da tributação extrafiscal tem por finalidades, entre outras, a redistribuição de renda e de terras, a defesa da indústria nacional, a orientação de certos investimentos em setores estratégicos de produção, e, também, o incentivo a jovens que carecem de ações efetivas de cidadania que, por diferentes fatores, foram excluídos do processo educacional, de modo a reduzir situações de risco, desigualdade, discriminação e outras vulnerabilidades sociais, fomentando sua participação social e cidadã enquanto cidadãos por completo.

Nesse contexto, Silva ${ }^{34}$ lembra que o valor finalístico da extrafiscalidade, que atribui o legislador à norma tributária, deve atender ademais da condução econômica, a correção de situações econômicas indesejadas, podendo inclusive fomentar "certas atividades ou ramo de atividades de acordo com os preceitos constitucionais ${ }^{35 "}$.

Sendo assim, toda a atividade legislativa e executiva deve ser orientada buscando o interesse social, sendo este um objetivo claro, que decorre da natureza prática das coisas em harmonia com o convivo social. E de igual maneira, a extrafiscalidade tributária exerce um papel de destaque na elaboração e aplicação de políticas públicas de desenvolvimento e inclusão social de jovens diante do atual cenário, sendo este, assunto do próximo capítulo.

\section{A EXTRAFISCALIDADE TRIBUTÁRIA ENQUANTO POLÍTICA PÚBLI- CA DE DESENVOLVIMENTO E DE INCLUSÃO SOCIAL DE JOVENS}

Como visto, a Constituição da República Federativa do Brasil de 1988 adotou a extrafiscalidade como um procedimento comum do direito tributário, principalmente como ferramenta de implementação de políticas públicas ao autorizar a exacerbação ou suavização do ônus fiscal. Como lembra Machado ${ }^{36}$, inicialmente o objetivo do tributo era a arrecadação de valores ao Estado, contudo, diante de um mundo moderno, o tributo passou a ser compreendido como uma medida eficaz de intervenção na economia, estimulação de atividades, setores, 
desestimulando/estimulando o consumo de determinados bens e dessa forma produzindo os mais variados efeitos na sociedade.

E, portanto, os principais mais basilares do direito trazidos pela Constituição, tais como a segurança jurídica, a justiça social e o bem comum, ligados diretamente com a efetivação dos direitos fundamentais, fazem-se presente principalmente na imunidade, isenção e benefícios fiscais, cuja sua natureza é extrafiscal.

Neste contexto, de acordo com Martins ${ }^{37}$ no arcabouço da extrafiscalidade estão previstas as condutas desejadas, aquelas que devem ser estimuladas, mas também estão as condutas indesejadas, que devem ser desestimuladas pelo legislador. Entretanto, não estão compreendidas as condutas contrárias ao ordenamento jurídico, tidas como proibidas, e, que, via de regra, são alvos das sanções negativas (penalidades). Por exemplo, quando da aplicação de multa por descumprimento de obrigação fiscal, o Estado exerce o controle social tradicional, guiado pela faculdade do ordenamento de caráter repressiva (coatora).

É diante desse contexto de função extrafiscal do tributo que Bonavides ${ }^{38}$ convida a todos para rever suas posições conservadoras e redesenhar as instituições e aplicações do Estado com base nas necessidades de um mundo contemporâneo. Dessa forma, deve buscar a imaginação coletiva das sociedades, refutando o racionalismo dos publicistas que encarcera as instituições no imobilismo e na repetição, "como se já houvesse no quadro dos conceitos e das fórmulas sobejamente conhecidas uma resposta adequada a cada problema ou a cada desafio que surgisse" 39 .

Portanto, a reformulação do pensamento atual deve ser pautada pela busca uma política pública fiscal que tenha por finalidade a contemplação dos interesses públicos voltados efetivamente à coletividade, sendo este um processo público com a participação de todos os interessados, para que juntos possam objetivar a justiça social de fato.

Partindo-se do pressuposto da existência de uma justiça social de fato, tem-se uma sociedade que inclui a todos somente porque é possível, ao mesmo tempo, excluí-los. Este problema deve ser afrontado também pelos economistas, tendo em mente a perspectiva da justiça não no sentido utilitarista. Não se pode esquecer que o utilitarismo tem, ainda, uma grande influência nos definidores de políticas públicas, tanto nacionais quanto internacionais. Quanto à 'política fiscal redistributiva' de se pretender uma distribuição desejável de rendas diante da perpetuação das grandes desigualdades verificadas na sociedade. ${ }^{40}$

Sendo assim, a elaboração, implementação e execução de políticas públicas devem ter como prioridade estratégias para o alcance de melhores condições de vida para o indivíduo e a sociedade. De tal modo, segundo Silva e Souza-Lima ${ }^{41}$, as políticas devem ter parâmetros determinados de mensuração, para que viabilize o acompanhamento no decorrer do percurso, podendo amadurecer sustentavelmente e expressar de forma contundente indicadores de sua efetividade. 
Nessa conjuntura, as políticas públicas tornaram-se ferramentas adequadas para a efetivação das ações políticas e desse modo a concretização de direitos fundamentais e sociais. Para tanto, imperioso que se faça uma abordagem dos conceitos metodológicos das políticas públicas. Em vista disso, a análise das políticas públicas tem desempenhado importante papel no aperfeiçoamento da compreensão do funcionamento das instituições públicas, principalmente nos tempos atuais. Desse modo, Schmidt ${ }^{42}$ afirma que "investigando os resultados, as políticas (policies) entende-se melhor os processos (politics) e o aparato institucional (polity) da política”.

Nesse cenário, uma maneira de avaliar a efetivação de uma determinada política púbica, podendo ser a partir da função extrafiscal do tributo, é por meio do desenvolvimento e aplicação do Índice de Desenvolvimento Humano (IDH) e do Índice de Desenvolvimento Humano Municipal (IDH-M), onde diversos estudos publicados no Brasil possibilitaram uma aproximação no que se refere a compreensão e a utilização do índice por toda a sociedade, até mesmo no desenvolvimento de políticas públicas. Permitiram, esses índices, "uma avaliação mais abrangente do nível de desenvolvimento humano do País e das precárias condições sociais que afligem boa parte da população, principalmente nas regiões menos desenvolvidas" ${ }^{43}$

Assim, as políticas públicas podem ser compreendidas como o resultado da política, das instituições e até mesmo de seus procedimentos. Dessa forma, quem estabelece o desmembramento entre esta e aquelas ignora a essência de ambas. Onde "a abordagem sistêmica, aqui apresentada, tem o grande mérito de evidenciar os estreitos liames das políticas com o conjunto dos componentes de um sistema político (instituições, processos, atores, arenas, lideranças, cultura política)" ${ }^{44}$

Diante desse ambiente de inclusão social de indivíduos excluídos, tem-se uma parcela da juventude brasileira que se vê a margem do sistema de proteção dos direitos fundamentais. Esse fenômeno reflete o esgotamento do modelo desenvolvimentista como afirma $\mathrm{Abramo}^{45}$, onde as reformas de caráter social com cunho liberal questionaram os direitos sociais até então consagrados. E a partir disso, enfraqueceram os instrumentos corporativistas fundados na solidariedade e no fortalecimento de critérios ligados com a competição no mercado e à individualização dos riscos.

E como mecanismo de combate a este cenário, lembra Rodrigues:

[...] a utilização extrafiscal de tais espécies tributárias pode ocorrer tanto em razão do grau de pobreza de determinadas pessoas como enquanto instrumento que vise, por exemplo, à geração de empregos para habitantes de determinado Município, o que se daria pela não cobrança de taxas, por período determinado, ou pela não cobrança de contribuições de melhoria decorrentes de obras. ${ }^{46}$

Acrescente-se, em âmbito municipal, as possibilidades, ainda, de incentivos fiscais relativamente ao IPTU, ao ITBI e ao ISS, principalmente quanto a este último para empresas prestadoras de serviços. 
Portanto, a implementação de políticas públicas com base na função extrafiscal da norma tributária reflete em toda a fundamentação do Estado Contemporâneo, uma vez que surge como um mecanismo institucional legítimo de formulação, mecanização e implementação para que uma política pública possa ser enquadrada como viável. Corroborando com esse entendimento, Silva relembra que a "finalidade extrafiscal da norma tributária constitui-se na aplicação de um modelo jurídico-tributário para a consecução de objetivos que preponderam sobre os fins simplesmente arrecadatórios de recursos financeiros para o Estado". ${ }^{47}$

E nesse contexto, incumbe à lei tributária atender as necessidades da sociedade por meio da finalidade extrafiscal, ao ordenar a condução da economia, corrigir determinadas situações sociais ou até mesmo possibilitar a promoção de ramos de atividades consoantes com os preceitos constitucionais. De natureza idêntica, o Estado comprometido com as suas finalidades sociais exercita, no entendimento de Martins ${ }^{48}$, seu papel enquanto agente transformador da realidade social, utilizando-se para isso políticas públicas para a juventude, posto que:

As primeiras demandas em relação à inserção produtiva e à inclusão social de jovens foram publicamente apresentadas por diferentes atores políticos e sociais, direta ou indiretamente interessados no tema. Tais iniciativas envolveram organismos internacionais, gestores e políticos nacionais, organizações não governamentais, organizações empresariais, setores de igrejas e, também, um conjunto de grupos, redes e movimentos juvenis. Ou seja, em um processo de mão dupla, diferentes atores políticos (organizações de apoio e de juventude) tomaram para si a iniciativa de anunciar publicamente a existência de 'problemas de juventude. ${ }^{49}$

Consequentemente, busca-se a construção de uma outra globalização, a qual seja menos excludente. Uma globalização que traga/comporte esperança àqueles em que ela não se evidencia como elemento de uma realidade inclusiva. Uma globalização, a partir de uma nova racionalidade, de um pensamento convergente na construção de um universalismo que contemple a todos iguais condições/possibilidades. ${ }^{50}$

E a partir disso, na concepção de Martins ${ }^{51}$ surge a compreensão de que o ordenamento jurídico pode desempenhar um papel fundamental na maneira de cooperação e compartilhamento das responsabilidades sociais, essencialmente na promoção de comportamentos sociais desejados por meio da função extrafiscal do tributo. E neste ambiente, no Brasil, mais precisamente em agosto de 2013, a juventude pode reacender a chama da esperança, com a edição do Estatuto da Juventude que prevê que direitos já elencados possam ser aprofundamentos e efetivamente garantidos atendendo as necessidades específicas dos jovens, respeitando assim a sua trajetória e diversidade. 


\section{CONSIDERAÇÕES FINAIS}

Por essas razões que o Estado, enquanto agente promotor e difusor de direitos e garantias fundamentais, se apresenta como um dos responsáveis diretos pela concretização dos direitos da juventude. E essa atuação é objetivada por meio das políticas públicas, tornando-se evidente que essas devem ser formuladas e implementadas de maneira a promover de forma efetiva os direitos e garantias de jovens.

Diante dessa perspectiva, a implementação de políticas públicas baseadas na função extrafiscal do tributo tem como propriedade a correção de externalidades, sejam elas positivas ou negativas. Podendo ter sua finalidade aplicada à juventude, quando, por exemplo, incentiva a geração de empregos ou quando utilizada como mecanismo viabilizador do ingresso de estudantes carentes no ensino superior, com a finalidade de organizar a vida em sociedade e a nivelação dos tipos e modos de viver.

Deste modo, as ações do poder público devem ser focadas no cidadão e no bem-estar da coletividade, por isso que a participação cidadã se torna relevante. Ninguém melhor que os legítimos detentores da soberania - o povo - para promover processos dinâmicos de discussões e debates sobre suas demandas, a fim de levá-las ao governo para a sua efetivação, e de pano de fundo, promover-se na prática a garantia de uma série de direitos da juventude.

Portanto, não se pode combater problemas oriundos do processo da globalização e de exclusão com programas assistencialistas, dado que, quando esses programas forem interrompidos, pelos mais diversos fatores, necessitados continuarão a sofrer. À vista disso, deve-se buscar a implementação de políticas públicas com base na extrafiscalidade da norma tributária como fomentadora da economia, da qualificação da educação para crianças e da geração de oportunidades de empregos para a juventude.

\section{REFERÊNCIAS}

ABAD, Miguel. Crítica política das políticas de juventude. In: PAPA, F. C.; FREITAS, M. V. (Orgs.). Políticas Públicas: Juventude em pauta. São Paulo: Cortez: Ação Educativa Assessoria, Pesquisa e Informação: Fundação Friedrich Ebert, 2003.

ABRAMO, Helena. Secretaria Nacional de Juventude. Estação juventude: conceitos fundamentais - ponto de partida para uma reflexão sobre políticas públicas de juventude. Brasília: SNJ, 2014.

. Considerações sobre a tematização social da juventude no Brasil. Revista Brasileira de Educação. São Paulo, ANPED n. 5-6, 1997, pp. 25-36.

ATALIBA, Geraldo. Hipótese de incidência tributária. São Paulo: Malheiros, 1997. 
BALTHAZAR, Ubaldo Cesar. Manual de direito tributário. Florianópolis: Diploma Legal, 1999.

BERTI, Flávio de Azambuja. Impostos, extrafiscalidade e não confisco. 3. ed. Curitiba: Juruá, 2009.

BONAVIDES, Paulo. Reflexões: política e direito. 3. ed. São Paulo: Malheiros, 1998.

BOURDIEU, Pierre. Questões de Sociologia. Rio de Janeiro: Marco Zero, 2005.

BRUNO, Jézica. Trabalho aos 14 anos tramita no Congresso. Jornal Correio do Povo. Porto Alegre, 31 ago. 2015.

GAZETA DO SUL. Jovem procura trabalho e desemprego sobe para 8,3\%. Jornal Gazeta do Sul. Santa Cruz do Sul, 26 ago. 2015.

GOUVEAA, Marcus de Freitas. A extrafiscalidade no direito tributário. Belo Horizonte: Del Rey, 2006.

MACHADO, Hugo de Brito. Curso de direito tributário. São Paulo: Malheiros, 1997.

MARTINS, Vinicius Malta. A função promocional do direito tributário na extrafiscalidade por estímulos: o direito como indutor de uma cidadania ativa e participante. 2009. 139 f. Dissertação (Programa de Pós-Graduação em Direito - Mestrado e Doutorado)-Universidade de Santa Cruz do Sul, Santa Cruz do Sul, 2009. Orientador: RODRIGUES, Hugo Thamir.

MARTUSCELLI, Fernando José Dutra. Elementos de direito tributário. Campinas: Bookseller, 2001.

NABAIS, José Casalta. O dever fundamental de pagar impostos: contributo para a compreensão constitucional do estado fiscal contemporâneo. Coimbra: Almedina, 2012.

OLIVEIRA, José Domingues de. Direito tributário e meio ambiente: proporcionalidade, tipicidade aberta, afetação da receita. 2. ed. Rio de Janeiro: Renovar, 1999.

RIZZINI, Irene. O século perdido: raízes históricas das políticas públicas para a infância no Brasil. 3. ed. São Paulo: Cortez, 2011.

RODRIGUES, Hugo Thamir. Harmonização solidária das políticas tributárias municipais: um princípio constitucional geral, implícito, delimitador das ações tendentes ao cumprimento da função social dos municípios. 2003. 275 f. Tese (Programa de Pós-Graduação em Direito - Doutorado) - Universidade Federal de Santa Catarina, Florianópolis, 2003. Orientador: BALTHAZAR, Ubaldo Cesar.

RUA, Maria das Graças. As políticas públicas e a juventude dos anos 90. In: Jovens acontecendo na trilha das políticas públicas, v. 2. Brasília: CNPD, 1998, p. 731-752. 
SANTOS, Milton. Por uma outra globalização: do pensamento único à consciência universal. 6. ed. Rio de Janeiro: Record, 2001.

SCHMIDT, João Pedro. Para entender Políticas Públicas: aspectos conceituais e metodológicos. In: REIS, J. R.; LEAL, R.G. (Orgs.). Direitos Sociais e Políticas Públicas: desafios contemporâneos. Santa Cruz do Sul: EDUNISC, 2008, t. 8 pp. 2307-2333.

SCHOUERI, Luís Eduardo. Normas tributárias indutoras e intervenção econômica. Rio de Janeiro: Forense, 2005.

SILVA, C. L.; SOUZA-LIMA, J. E. Políticas Públicas e indicadores para o desenvolvimento sustentável. São Paulo: Saraiva, 2010.

SILVA, Daniel Cavalcanti. A finalidade extrafiscal do tributo e as políticas públicas no Brasil. Revista Primas: Direito, políticas públicas e mundialização. Brasília, v.4, n, 1, pp. 98-122, jan/jul. 2007.

TIPKE, Klaus; LANG, Joachim. In: FURQUIM, Luiz Dória (Trad.). Direito Tributário. Porto Alegre: Sergio Antonio Fabris Editor, 2008, v. I.

VIAL, Sandra Regina Martini. Demandas sociais e políticas públicas na sociedade contemporânea. In: Anais do II Seminário Internacional Demandas Sociais e Políticas Públicas na Sociedade Contemporânea. Porto Alegre: Evangraf, 2005.

ZERO HORA. Aumenta a procura por vagas e desemprego sobe. Jornal Zero Hora. Porto Alegre, 26 ago. 2015.

1 O termo "nação" é visto, aqui, a partir de uma perspectiva histórica, envolvendo seu passado, o seu presente e o seu futuro.

2 RIZZINI, Irene. O século perdido: raízes históricas das políticas públicas para a infância no Brasil. 3. ed. São Paulo: Cortez, 2011, p. 45.

3 Ibidem, p. 45.

4 ABAD, Miguel. Crítica política das políticas de juventude. In: PAPA, F. C.; FREITAS, M. V. (Orgs.). Políticas Públicas: Juventude em pauta. São Paulo: Cortez: Ação Educativa Assessoria, Pesquisa e Informação: Fundação Friedrich Ebert, 2003.

5 ABRAMO, Helena. Considerações sobre a tematização social da juventude no Brasil. Revista Brasileira de Educação. São Paulo, ANPED n. 5-6, 1997, pp. 25-36.

6 Ibidem, p. 14.

7 ABAD, op. cit.

8 ABRAMO, Helena. Secretaria Nacional de Juventude. Estação juventude: conceitos fundamentais - ponto de partida para uma reflexão sobre políticas públicas de juventude. Brasília: SNJ, 2014, p. 20.

9 ABAD, op. cit.

10 ABRAMO, 2014, p. 19.

11 Ibid., .

12 SILVA, C. L.; SOUZA-LIMA, J. E. Políticas Públicas e indicadores para o desenvolvimento sustentável. São Paulo: Saraiva, 2010, p. 46.

13 SCHMIDT, João Pedro. Para entender Políticas Públicas: aspectos conceituais e metodológicos. In: REIS, J. R.; LEAL, R.G. (Orgs.). Direitos Sociais e Políticas Públicas: desafios contemporâneos. Santa Cruz do Sul: EDUNISC, 2008, t. 8, p. 2308. 
14 SILVA; SOUZA-LIMA, op. cit.

15 ABAD, op. cit.

16 SILVA; SOUZA-LIMA, op. cit., p. 49.

17 RUA, Maria das Graças. As políticas públicas e a juventude dos anos 90. In: Jovens acontecendo na trilha das políticas públicas, v. 2. Brasília: CNPD, 1998, p. 731.

18 ABAD, op. cit.

19 ABRAMO, 2014, et. seq.

20 BRUNO, Jézica. Trabalho aos 14 anos tramita no Congresso. Jornal Correio do Povo. Porto Alegre, 31 ago. 2015.

21 ZERO HORA. Aumenta a procura por vagas e desemprego sobe. Jornal Zero Hora. Porto Alegre, 26 ago. 2015.

22 GAZETA DO SUL. Jovem procura trabalho e desemprego sobe para 8,3\%. Jornal Gazeta do Sul. Santa Cruz do Sul, 26 ago. 2015, p. 11.

23 ATAliBA, Geraldo. Hipótese de incidência tributária. São Paulo: Malheiros, 1997.

24 GOUVÊA, Marcus de Freitas. A extrafiscalidade no direito tributário. Belo Horizonte: Del Rey, 2006, p. 175, grifo original.

25 BALTHAZAR, Ubaldo Cesar. Manual de direito tributário. Florianópolis: Diploma Legal, 1999.

26 Cf. NABAIS, José Casalta. O dever fundamental de pagar impostos: contributo para a compreensão constitucional do estado fiscal contemporâneo. Coimbra: Almedina, 2012, p. 629: "A extrafiscalidade traduz-se no conjunto de normas que, embora formalmente integrem o direito fiscal, tem por finalidade principal ou dominante a consecução de determinados resultados econômicos ou sociais através da utilização do instrumento fiscal e não a obtenção de receitas para fazer face às despesas públicas. Trata-se assim de normas [...] que [...] estão dominadas pelo intuito de actuar diretamente sobre os comportamentos económicos e sociais dos seus destinatários, desincentivando-os, neutralizando-os nos seus efeitos económicos e sociais ou fomentado-os, ou seja, de normas quem contêm medidas de política económica e social.

27 TIPKE, Klaus; LANG, Joachim. In: FURQUIM, Luiz Dória (Trad.). Direito Tributário. Porto Alegre: Sergio Antonio Fabris Editor, 2008, v. I, p. 177.

28 BERTI, Flávio de Azambuja. Impostos, extrafiscalidade e não confisco. 3. ed. Curitiba: Juruá, 2009, p. 41

29 SILVA, Daniel Cavalcanti. A finalidade extrafiscal do tributo e as políticas públicas no Brasil. Revista Primas: Direito, políticas públicas e mundialização. Brasília, v.4, n, 1, p. 98-122, jan/ jul. 2007, p. 117.

30 SCHOUERI, Luís Eduardo. Normas tributárias indutoras e intervenção econômica. Rio de Janeiro: Forense, 2005, passim.

31 MARTINS, Vinicius Malta. A função promocional do direito tributário na extrafiscalidade por estímulos: o direito como indutor de uma cidadania ativa e participante. 2009. $139 \mathrm{f}$. Dissertação (Programa de Pós-Graduação em Direito - Mestrado e Doutorado)-Universidade de Santa Cruz do Sul, Santa Cruz do Sul, 2009, passim.

32 MARTUSCELLI, Fernando José Dutra. Elementos de direito tributário. Campinas: Bookseller, 2001.

33 MARTINS, op. cit., p. 101.

34 SILVA, op. cit., p. 100.

35 Art. 227. É dever da família, da sociedade e do Estado assegurar à criança, ao adolescente e ao jovem, com absoluta prioridade, o direito à vida, à saúde, à alimentação, à educação, ao lazer, à profissionalização, à cultura, à dignidade, ao respeito, à liberdade e à convivência familiar e comunitária, além de colocá-los a salvo de toda forma de negligência, discriminação, exploração, violência, crueldade e opressão. § $8^{\circ}$ A lei estabelecerá: I - o estatuto da juventude, destinado a regular os direitos dos jovens; II - o plano nacional de juventude, de duração decenal, visando à articulação das várias esferas do poder público para a execução de políticas públicas. (BRASIL. Constituição da República Federativa do Brasil de 1988). 
36 MACHADO, Hugo de Brito. Curso de direito tributário. São Paulo: Malheiros, 1997, passim.

37 MARTINS, op. cit.

38 BONAVIDES, Paulo. Reflexões: política e direito. 3. ed. São Paulo: Malheiros, 1998.

39 Ibidem, p. 218.

40 VIAL, Sandra Regina Martini. Demandas sociais e políticas públicas na sociedade contemporânea. In: Anais do II Seminário Internacional Demandas Sociais e Políticas Públicas na Sociedade Contemporânea. Porto Alegre: Evangraf, 2005, s/p, grifo original, passim.

41 SILVA; SOUZA-LIMA, op. cit.

42 SCHMIDT, op. cit., p. 2330.

43 SILVA; SOUZA-LIMA, op. cit., p. 152.

44 SCHMIDT, op. cit., p. 2330.

45 ABRAMO, op. cit.

46 RODRIGUES, Hugo Thamir. Harmonização solidária das políticas tributárias municipais: um princípio constitucional geral, implícito, delimitador das ações tendentes ao cumprimento da função social dos municípios. 2003. 275 f. Tese (Programa de Pós-Graduação em Direito - Doutorado) - Universidade Federal de Santa Catarina, Florianópolis, 2003, p. 203.

47 SILVA, Daniel Cavalcanti. A finalidade extrafiscal do tributo e as políticas públicas no Brasil. Revista Primas: Direito, políticas públicas e mundialização. Brasília, v.4, n, 1, p. 98-122, jan/ jul. 2007, p. 119.

48 MARTINS, et. seq.

49 ABRAMO, op. cit., p. 113.

50 SANTOS, Milton. Por uma outra globalização: do pensamento único à consciência universal. 6. ed. Rio de Janeiro: Record, 2001, passim.

51 MARTINS, et. seq.

\title{
PUBLIC POLICIES AND EXTRAFISCALITY: FUNDAMENTAL RIGHTS OF BRAZILIAN YOUTH
}

\begin{abstract}
The aim of this study is to analyze the relationship between public policy and extrafiscality of taxes based on the public action to entrench fundamental rights of Brazilian youth. Given this scenario, the role of government in building effective public policies in this regard is pointed out. The extrafiscality purpose of the tax law as implementation of public policy engine is presented. Starting from that, we analyze the possibilities and the development of public policies with the aim of socially including young people in the Brazilian frame.
\end{abstract}

Keywords: Extrafiscality function; Fundamental rights; Public policies; Youth.

Submetido: 25 nov. 2015

Aprovado: 5 jan. 2016 